\title{
A Elaboração Legislativa e o Assessor
}

\section{Eduardo Aniento}

O tema que aqui focalizo, embora muito discutido, valerá mais como uma simples adaptação do que, pròpriamente, como doutrina. E' sabido que outros paises de regime democrático, notadamente os E. U. A.. já mantêm no Congresso, na Presidência e em vátias instituições de interêsse coletivo verdadeiras assessorias parlamentares. Indubitàvelmente, a excelência do sistema adotado fica comprovada. quando fàcilmente se pode verificar a presteza e qualidade dos trabalhos apresentados. (N. A.)

A Elaboração Legislativa realiza-se em três etapas, tôdas revestidas da máxima importância, a pré-legislativa, a legislativa e a pós-legislativa. $\mathrm{Na}$ fase inicial, surge a pré-legislativa, como sendo apænas um corpo que precisa ser cuidadosamente vestido; dessa indumentária, muito dependerá o seu êxito, no caminho que deve prosseguir. É o nascimento da legislação e, vale dizer, dada a sua extraordinária semelhança com o ser humano, deve-se prestar-lhe o maior cuidado, objetivando evitar o seu atrofiamento ou morte, no nascedouro.

Dısta forma, a preocupação primeira será sempre a informação através da colheita, dos elementos que interessem ao assunto, obtida das fontes mais idôneas é de indiscutivel crédito. Nessa coleta, devem figurar, invariàvelmente, quaisquer dispositivos legais anteriores e correlatos com a matéria a ser tratada, criando desde logo, a completa conciliação com os preceitos constitucionais da República, visando, destarte, ao entrosamento perfeito e harmônico com as normas em vigor.

Em seguida, para formular a definição conceitual, utilizam-se os elementos já obtidos e, após a devida confirmação, selécionarse o indispensável ao caso, delineando-se assim, a formação estrutural do projzto. Formulada a estrutura, deve-se dar-lhe a redação formal, o que constitui um ponto alto na confecção do diploma legal. Êste momento, reclama a atenção para a observância da linguagem utilizada, que deve escapar ao rigorismo técnico. Neste particular, é de lembarr o C. Ilbert, em «Legislative Methods and Forms», que define a linguagem correta, como resultante da coligação entre a tendência técnica e a popular.

Arthur Giry, em sua publicação, "Thechnique Legislative», divide" tècnicamente a lei em duas partes, texto e protocolo, considerando a primeira

( * Trabalho apresentado no Curso de Assessor Parlamentar, ministrado pelo Instituto Brasileiro de Cidadania e Administração. 
como o trecho da lei que enuncia, imperativamente, a vontade do legislador, e a segunda, como um conjunto de fórmulas que precedem e sucedem ao texto.

Por outro lado, o eminente Montesquieu observa, em "L'Esprit de Loi», que as leis devem sar concisas e simples, para serem vistas e compreendidas por todos.

Benthan, em «Introduction to Principles of Moral and Legislation», com sua técnica legislativa, processos, métodos e forma codificada, afirma que os estudos das leis, dependem da lógica e da gramática. Êste notảvel autor, proclamava ainda que a lei deve representar exatamente a «mens legislatoris» e reunir um todo que facilite a sua fixação na mente, eliminando ao máximo o excesso de minúcias, repetições inúteis e definições desnecessárias, dando-lhe, porém, uma eloquiência especial, destinada p:lo menos à conquista do favor popular.

Completando a lição dos clássicos, vemos, em «La Funcione Legislativa», de Meuccio Ruin, que embora variáveis o estilo e a técnica legislativa, nunca, entrctanto, devem as proposições serem iniciadas com o gerúndio ou advérbio; o vocábulo «pode» sòmente deve ser usado quando se tratar de uma faculdade, e a norma legal deve ser a enunciação pura e simples da vontade do legislador, sem incluir razões ou opiniões de sua natureza.

Sendo, de fato, a redação formal a parte conclusiva da fase preparatória da lei, é necessàriamente importante manter-se o sistema dentro do corpo legal, evitando-se, também, a todo custo, o «non liquiet».

De qualquer modo, a jurisprudência deve ser consultada, pois o rerfeito conhecimento da doutrina é de capital importância e, de maneira especial, quando novas diretrizes visem disciplinar as diversas instituições juridico-sociais .

Outro fator, que merece tôda a atenção, é a parte referente aos requisitos formais, estabelecidos pelos Regimentos, os quais constituem condição «sine qua non» para que os projetos sejam aceitos pela Mesa das Câmaras, cuja competência é rzceber e encaminhar a proposições. Em geral, todo Regimento de qualquer Câmara, mesmo do exterior, estabelece os requisitos formais que os projetos devem apresentar para serem recebidos pela Mesa.

Tomando-se como exemplo o Regimento da Câmara Federal dos Deputados, temos sob o Título IV, das Proposiçóes, Capítulo I, as Disposições Gerais, definindo a proposição e dispondo no $\S 2$ do art. 88 que «tôda proposição deverá ser red:gida com clareza, em têrmos explícitos e sintéticos, e apresentada em 3 vias». Além de estabelecer um critério, dispõe ainda, das condições indispensávzis à matéria, pois no $\S 3^{\circ}$ encontramos que «A Presidência devolverá ao seu autor qualquer proposição que versar matéria: alheia à competência da Câmara; evidentemente inconstitucional; anti-regimental; que tznha expressão ofensiva a quem quer que seja».

$\mathrm{Na}$ redação de um projeto, iniçialmente vem o titulo, que pode ser projeto de lei, projeto de décreto legislativo ou proj:to de resolução. No caso de um projeto de lei, por hipótese, a redação seria da seguinte forma: 
Projeto de lei - Número e Ano - logo abaixo a Émenta, ou seja, a enunciação resumida do objetivo contido no texto. Em seguida, a autoria, usando-se a expressão: «Do Sr. Fulano de tal». Logo a seguir, viria: «O Congresso Nacional Decreta». Depois, então, teriamos o texto, devidamente articulado, disciplinando a matéria, e no item final quando entrará em vigor (em geral na sua publicação), terminando com a data e assinatura do seu autor.

Concluída a redação do projeto pròpriamente dito, seria elaborada a justificação, onde' o autor defenderia os motivos e viabilidade da execução legal da matéria focalizada.

Terminada a fase pré-legislativa, a proposição apresenta-se ao Congresso, para a fase legislativa, onde serão apuradas as exigências formais e os requisitos do mérito. Neste estágio é que se désenvolve o trabalho legislativo, pois nesta oportunidade, atuam as Comissões, discute-se a matéria, submetendo a, a seguir, à decisão do plenário. Nesta etapa dé alta relevância, que constitui a fase final, a proposição será defendida ou combatida pelos discursos, questões de ordem, técnicas de obstrução e aceleração, terminando quando o projeto é votado.

Ressalvada a competência exclusiva do Congresso, nos projetos legislativos ou de resolução, irá o projeto ao Presidente da República para sanção ou veto. Se fôr vetado, sofrerá novo estudo, principalmente em fac: do disposto no art. $70 \S \S 1^{\circ}$ e $3^{\circ}$ da Constituição. A sanção, realmente, constitui a regra e sendo o veto um ato excepcional, êste deverá sar muito bem fundamentado.

$\mathrm{Na}$ fase legislativa, podem participar o Congresso e o Presidente da República, que embora respeitando o critério de serem os Podêres independentes e harmônicos entre si, ficam, invariàvelmente, os seus atos, subordinados sempre às limitações constitucionais.

A última fase da Elaboração Legislativa é, sem dúvida, a pos-legislativa, tendo como atividades principal, a publicação, o acompanhamento da execução da lei, notadamente, o Orçamento, Leis Financeiras, Lei Eleitoral e, ainda, o procedimento da correção de diplomas legais, que, na prática, se revelem inábeis.

Diante de tôda essa tramitação, o Asessor na Elaboração Legislativa deve ocupar, nécessàriamente, a importante posição de sociólogo na sociologia, sempre pesquisando e adotando novas formas para melhor definir e utilizar os seus conhecimentos. Funcionará êle como o elemento inteligência, intimamente associado à vontade do legislador, dentro da complexidade daquela gigantesca esfera de inadequados e penosos recursos.

Entendendo-se o Congresso, em analogia com uma maternidade, sentiremos de imediato, por certo, a mesma correlação, ambos desempenham função importantíssima na Sociedade. Entretanto, a Maternidade moderna possui todo o equipamento material e pessoal necessário ao seu bom funcionamento, o que infelizmente ainda não ocorre em nosso Congre'sso, muito embora estejamos vivendo em plena época do tecnicismo, com notáveis exemplos do exterior. 
Especialmente e'm nosso regime de Govêrno, estou deveras convencido de que o ideal seria a criação de uma Assessoria, como órgão institucional, onde estivesse representada a cultura, como a definiu EDWARD BURNETT TYLOR, $e_{m}$ «P rimitive Culture», dizendo que a cultura é um todo complexo que inclui os conhecimentos, a crença, a arte, a moral, o direito, o costume e qualquer outra capacidade adquirida pelo homem como membro da sociedade.

O assessoramento sendo prestado através de um órgão autônomo, não apenas seria mais eficiente, porém, sobretudo, visaria eliminar ao máximo o «errare humanun est», proporcionando melhor qualidade nos trabalhos, sem contudo, alterar a vontade do consulente quando esta tivesse um minimo de possibilidade. Enfim, os trabalhos seriam sempre realizados, a ex-consensu de legislador, que iria admitindo na prática a técnica tão indiscutivelmente necessária, que em pouco tempo viria, sem dúvida, substituir a quantidade pela qualidade e, então, principalmente no Congresso, seria reduzido ao xninimo a legislação de favor e outras inadmissiveis, diminuindo, sensivelmente o volumoso expediente legislativo, criando, em consequiencia, possibilidades para que projetos de maior interêsse sejam tratados.

A assessoria, assim concebida, seria composta de vários departamentos, cada qual profundamente capacitado dentro de suas atribuições, proporcionando ao legislador o mais rápido e perfeito serviço, que iria desde a fornecimento de dados até à confecção do projeto, se assim o desejasse.

Uma das caracteristicas principais dêsse órgão, seria a de viver verdadeiramente na realidade social, com métodos especiais destinados a colecionar e aplicar os estudos conseguidos, estabelecendo «in limine» para a sua formação, um critério rigoroso, sempre pelo mérito e nunca politico.

Nesse sentido, a atuação do parlamentar se faria sentir mais acentuada, como um verdadeiro politico, na mais ampla acepção do vocábulo, consequindo, inclusive, não apenas os elementos-completos de estudos da matéria, mas, sobretudo, o precioso tempo, para que realmente pudesse sua palavra, no Congresso, encontrar maior campo de ação, sobressaindo-se desta forma, com mais notoridade, ante o testemunho da nação e de seus correligionários. Em sintese, teria o parlamentar maior e melhor produção, com muito menor gasto de energias, podendo-se dedicar com enorme possibilidade de êxito, mais vigorosamente, na defesa de seus projetos, tècnicamente elaborados e possuidores de considerával conteúdo de interêsses positivos para a sociedade. Destacar-se-ia o legislador com visivel patriotismo, no mais puro exercíc:o de suas atividades parlamentares. 